\title{
Anaesthesia Experience for Breast Surgery with Ultrasound-Guided Pecs Block II in High-Risk Elderly Patients - Two Case Reports
}

\author{
Cengiz Kaya ${ }^{1}$, Burhan Dost ${ }^{2}$, Yasemin Burcu Ustun ${ }^{3}$
}

1,2,3 Department of Anaesthesiology, Ondokuz Mayis University, School of Medicine, Kurupelit, Samsun, Turkey.

\section{INTRODUCTION}

The incidence of breast cancer has increased significantly over recent years. ${ }^{1}$ Surgery is the gold standard treatment for most cases, and general anaesthesia (GA) is the preferred anaesthetic technique. However, regional anaesthesia may be an alternative to GA in multimodal regimens in high-risk patients to avoid GA-related cardiovascular or pulmonary side effects. ${ }^{2}$ The use of neuraxial techniques [thoracic epidural or thoracic paravertebral block (TPVB)] or an intercostal nerve block can therefore be suggested. ${ }^{3}$ However, novel approaches that are easier, safer, and more effective have been proposed to overcome possible complications and difficulties of these techniques. One approach, the pectoral nerve (Pecs) II block, is a fascial plane block that has shown promising results in anterolateral chest wall 2 analgesia.3,4 The aim of this technique is to block the pectoral nerves, intercostobrachial, intercostals ${ }^{3-}$ ${ }^{6}$ and the long thoracic nerve. ${ }^{4}$ The Pecs block II has been used successfully as part of the multimodal regimen for postoperative analgesia, but not yet as a primary anaesthetic technique in breast surgery. ${ }^{3}$ Here, we describe breast cancer resection with ultrasound (US)-guided Pecs block II and sedation in two high-risk elderly patients. Both patients provided written consent for publication of the case reports and related images.

Here, we present two breast cancer resection cases with multiple comorbidities who underwent ultrasound-guided Pecs II blocks under sedation. Additional analgesic and / or local anaesthetic infiltration was required for parasternal region pain (simple mastectomy, Case 1) and axillary region pain (sentinel node biopsy, Case 2). However, Pecs II blocks may not block the anterior cutaneous intercostal nerve branches or the intercostobrachial nerve in operations involving the medial part of the breast or extending to the axilla.

\section{PRESENTATION OF CASE}

\section{Case 1}

A 74-year-old female $(175 \mathrm{~cm}$ tall, weighing $85 \mathrm{Kg}$, and American Society of Anesthesiologists [ASA] IV) presented with a rapidly increasing left breast mass and was scheduled for a simple mastectomy. Preoperative assessment indicated hypertension and interstitial lung disease (ILD-GAP index 4). ${ }^{5} \mathrm{~A}$ physical examination revealed shortness of breath at rest and three-pillow orthopnea. Blood tests were normal, electrocardiograms showed sinus rhythm, and imaging (echocardiogram, chest X-ray, and computed tomography) appeared normal. The patient was receiving lercanidipine, telmisartan, and supplemental oxygen.
Corresponding Author:

Cengiz Kaya,

Department of Anesthesiology,

Ondokuz Mayis University,

School of Medicine,

Kurupelit, Samsun, Turkey.

E-mail: cengiz.kaya@omu.edu.tr

DOI: $10.14260 / j e m d s / 2021 / 158$

How to Cite This Article:

Kaya C, Dost B, Ustun YB. Anaesthesia experience for breast surgery with ultrasound-guided pecs block II in high-risk elderly patients: two case reports. J Evolution Med Dent Sci 2021;10(10):739742, DOI: $10.14260 /$ jemds/2021/158

Submission 23-10-2020,

Peer Review 14-01-2021,

Acceptance 20-01-2021,

Published 08-03-2021.

Copyright (c) 2021 Cengiz Kaya et al. This is an open access article distributed under Creative Commons Attribution License [Attribution 4.0 International (CC BY 4.0)] 


\section{Case 2}

A 75-year-old female ( $165 \mathrm{~cm}$ tall, weighing $78 \mathrm{Kg}$, and ASA IV) complained of swelling in the upper outer breast quadrant and was scheduled for segmental mastectomy and sentinel lymph node biopsy (SLNB). Preoperative assessment revealed diabetes mellitus, coronary artery disease, and congestive heart failure (NYHA class IV), mitral valve replacement surgery in 2014, and a drug-eluting stent implant four months previously. Preoperative examinations indicated limitation of physical activity and shortness of breath at rest. Preoperative blood tests were within normal limits. Electrocardiograms showed sinus rhythm, chest X-rays showed right pleural effusion with costophrenic angle blunting, and echocardiograms showed a moderate posterior pericardial effusion. She was using warfarin, furosemide, spironolactone / hydrochlorothiazide, and gliclazide. Warfarin was discontinued 5 days before surgery, with bridging therapy.

Considering the disadvantages of general anaesthesia in both patients, we planned US-guided Pecs block II with sedation. Both patients were informed about all potential risks and both consented to all procedures.

The patients were started on oxygen (flow rate $4 \mathrm{~L} / \mathrm{min}$ ) and remifentanil infusion after standard monitoring (noninvasive blood pressure, oxygen saturation, and electrocardiogram). The remifentanil infusion was initiated before the block and maintained until the end of surgery. Remifentanil was titrated to $0.05-0.1 \mu \mathrm{g} / \mathrm{Kg} / \mathrm{min}$ (Ramsay Sedation Scale) to enable communication with the patient. Both patients received ondansetron $(4 \mathrm{mg})$ for nausea / vomiting prophylaxis and paracetamol (1 gr) as an adjunct to multimodal analgesia.

\section{Description of the Block Technique}

The patients were placed in the supine position with the arm in $90^{\circ}$ abduction. Under strict aseptic conditions, the ultrasound linear probe (Logiq V1, GE, 8 - $13 \mathrm{MHz}$, China) was placed below the lateral third of the clavicle and moved inferolaterally to the anterior axillary line to allow viewing of the $3^{\text {rd }}$ and $4^{\text {th }}$ ribs and muscles (major-minor pectoralis and anterior serratus, from superficial to deep).

After infiltration of 1-2 mL $2 \%$ lidocaine into the puncture site, the block needle $(80-\mathrm{mm}, 21 \mathrm{G}$ short bevel; Stimuplex® Ultra $360 \AA$, B. Braun, Germany) was inserted and moved from a medial to a lateral direction, using the in-plane approach. The needle was passed through the major and minor pectoral muscles, and $20 \mathrm{~mL}$ of local anaesthetic (LA) $0.5 \%$ bupivacaine plus adrenaline 1:400000; Marcaine $\AA$, AstraZeneca, Turkey) were injected into the interfascial plane between the minor pectoral and anterior serratus muscles at the 3rd or 4 th rib level.

The needle was then withdrawn to the interfascial plane between the pectoralis major and minor muscles, where a further $10 \mathrm{~mL}$ of LA $(0.5 \%$ bupivacaine plus adrenaline 1:400000) was injected (Figures 1 and 2).

The surgical procedure was initiated after pinprick test confirmation of sensory block in the T2-6 dermatomes. Case 1 reported moderate pain during dissection of the inner breast quadrant and was treated with an increased infusion rate of remifentanil $(0.025-0.05 \mu \mathrm{g} / \mathrm{Kg} / \mathrm{min})$ and intravenous ketamine (30 mg total in divided doses) and with additional infiltration of $5 \mathrm{~mL} 2 \%$ lidocaine administered along the parasternal margin by the surgeon. Case 2 reported mild discomfort during the SLNB skin incision and during SLNB axillary incision and received local infiltration of $5 \mathrm{~mL} 2 \%$ lidocaine for both.
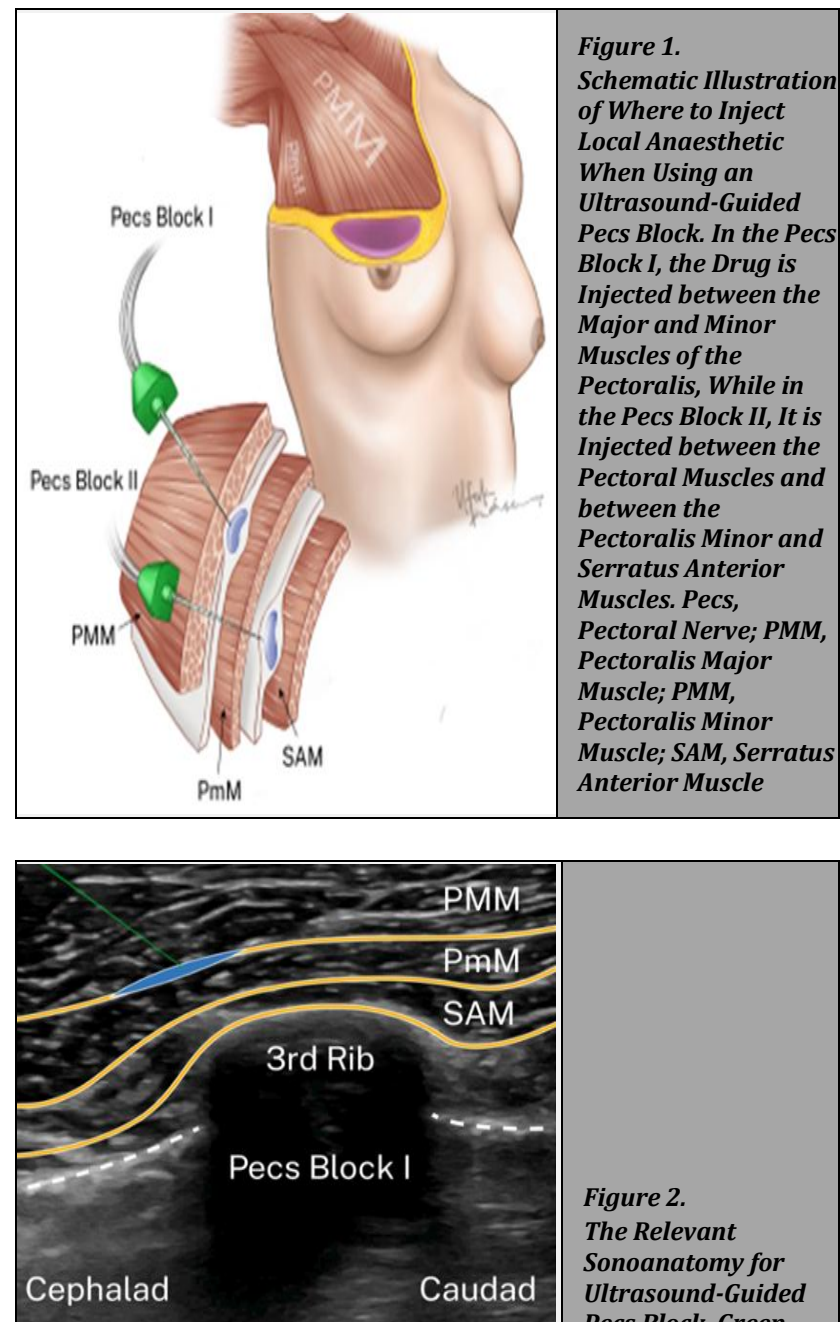

Figure 2.

The Relevant Sonoanatomy for Ultrasound-Guided Pecs Block. Green Line Represents the

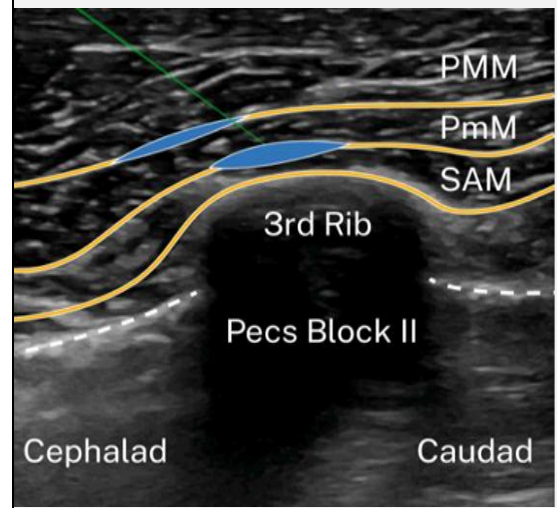

Needle Trajectory, Blue Highlighted Area is the Desired Spread of Local Anaesthetic, and the White Dashed Line Denotes the Pleura. Pecs, Pectoral Nerve; PMM, Pectoralis Major Muscle; PMM, Pectoralis Minor Muscle; SAM, Serratus Anterior Muscle

Both patients remained haemodynamically stable throughout the surgery. A mass of $14 \times 10.5 \times 9 \mathrm{~cm}$ was removed from Case 1 in a $65 \mathrm{~min}$ procedure. A $2.7 \times 3 \times 1.7 \mathrm{~cm}$ mass was removed from Case 2 in a 90 min procedure. Both patients were admitted for post-anaesthesia care and then transferred $2 \mathrm{~h}$ later to the general surgery ward with no analgesic or antiemetic requirements. Both patients received routine acetaminophen $(1 \mathrm{gr})$ every $8 \mathrm{~h}$, and neither reported any pain for $24 \mathrm{~h}$. Case 1 and Case 2 were discharged on postoperative first day, without complications. 


\section{DISCUSSION}

Our cases demonstrate that breast surgery can be performed without GA, even in elderly patients with significant comorbidities, by implementing a US-guided Pecs II block under sedation. The Pecs block has been used as an alternative to neuraxial techniques (e.g., thoracic epidural block and TPVB) to provide perioperative analgesia during breast surgery. ${ }^{2,6}$ TPVB, which is considered the gold standard for breast surgery analgesia, ${ }^{7-9}$ blocks the T2-T6 spinal nerves, and therefore all lateral and anterior cutaneous intercostal nerve branches. However, TPVB has associated complications (e.g., accidental intravascular injection, hypotension, intrathecalepidural dissemination, and pneumothorax) and technical difficulties; therefore, attention has shifted to easier and safer fascial plane blocks. ${ }^{4,7,10}$ Here, application of the Pecs II block was more suitable than TPVB in our two elderly cases.

Both our cases required additional analgesic and / or LA infiltration. In Case 1 (simple mastectomy performed without the operation extending to the axilla), the patient felt moderate pain around the parasternal incision. In fact, the failure to prevent the pain originating there with the Pecs II block was not surprising considering the breast innervation, as this region is innervated by the anterior cutaneous intercostal nerve branches. ${ }^{4}$ Some new approaches (such as the parasternal block or the transversus thoracic muscle plane block) have been described for blockade of these branches that are not within the target nerves of the Pecs II block.11,12 In Case 1 , the additional analgesic and LA infiltration might have been unnecessary had we combined one of these approaches with the Pecs II block.

In Case 2 (segmental mastectomy and SLNB), the location of the lesion in the upper outer quadrant eliminated the need for blockade of the anterior cutaneous branches, as in Case 1. However, our case required further LA infiltration because the operation involved the axillary region. Blocking the intercostobrachial nerve (T1-T2), which supplies the cutaneous innervation of the axillar region, may not always be possible with either the Pecs II block or the TPVB. ${ }^{13-15}$ However, the Pecs II block can block the branches of the brachial plexus (medial-lateral pectoral and long thoracic nerves) with two injections in the surface and deep fascial planes, thereby eliminating the pain arising from the deep axillary structures when the operation is extended to the axillary regions. ${ }^{14,15}$

In TPVB, a point to be kept in mind is that the branches of the brachial plexus cannot be reliably blocked since cervical extension may not be always present.13,11 In a study conducted on modified radical mastectomy cases, the lower postoperative morphine requirements and pain scores in a Pecs block group than in a TPVB group were attributed to better axillary analgesia by the Pecs block. ${ }^{10}$ Consequently, in Case 2, surgery could be finalised with LA infiltration alone, in addition to axillary incision, due to the location of the tumour and administration of adequate analgesia in deep axillary structures with the Pecs II block.

We believe that the Pecs II block may be a safer alternative than GA when administered with sedation / LA supplementation in patients with multiple comorbidities who require breast cancer surgery. However, regional techniques should be combined with complete surgical anaesthesia, depending on the location of the tumour and according to the complexity of breast innervation. For example, for surgeries involving the parasternal region, a technique that blocks the anterior cutaneous branches of the intercostal nerves should be planned in addition to the Pecs II block. Conversely, if the surgical site extends over to the axilla, the possibility should be kept in mind that the Pecs II block may not effectively block the intercostobrachial nerve and additional skin infiltration may be required.

Financial or other competing interests: None.

Disclosure forms provided by the authors are available with the full text of this article at jemds.com.

This case report was submitted as a poster presentation at the Turkish Society of Anesthesiology and Reanimation Congress, October 28 - 30, 2020, e-congress.

\section{REFERENCES}

[1] Ferlay J, Soerjomataram I, Dikshit R, et al. Cancer incidence and mortality worldwide: sources, methods and major patterns in GLOBOCAN 2012. International Journal of Cancer 2015;136(5):E359-86.

[2] Cassi LC, Biffoli F, Francesconi D, et al. Anaesthesia and analgesia in breast surgery: the benefits of peripheral nerve block. Eur Rev Med Pharmacol Sci 2017;21(6):1341-5.

[3] Versyck B, van Geffen GJ, Chin KJ. Analgesic efficacy of the Pecs II block: a systematic review and meta-analysis. Anaesthesia 2019;74(5):663-73.

[4] Blanco R, Fajardo M, Maldonado TP. Ultrasound description of Pecs II (modified Pecs I): a novel approach to breast surgery. Rev Esp Anestesiol Reanim 2012;59(9):470-5.

[5] Wells AU, Antoniou KM. The prognostic value of the GAP model in chronic interstitial lung disease: the quest for a staging system. Chest 2014;145(4):672-4.

[6] Annamalai G, Durairaj AK, Kailasam KR. Pectoral nerve block versus thoracic paravertebral block- comparison of analgesic efficacy for postoperative pain relief in modified radical mastectomy surgeries. Journal of Evolution of Medical and Dental Sciences 2017;6(60):4412-6.

[7] Batra RK, Krishnan K, Agarwal A. Paravertebral block. J Anaesthesiol Clin Pharmacol 2011;27(1):5-11.

[8] Moon EJ, Kim SB, Chung JY, et al. Pectoral nerve block (Pecs block) with sedation for breast conserving surgery without general anaesthesia. Ann Surg Treat Res 2017;93(3):166-9.

[9] Agarwal RR, Wallace AM, Madison SJ, et al. Single injection thoracic paravertebral block and postoperative analgesia after mastectomy: a retrospective cohort study. J Clin Anesth 2015;27(5):371-4.

[10] Kulhari S, Bharti N, Bala I, et al. Efficacy of pectoral nerve block versus thoracic paravertebral block for postoperative analgesia after radical mastectomy: a randomized controlled trial. $\mathrm{Br} J$ Anaesth 2016;117(3):382-6.

[11] Ueshima H, Kitamura A. Blocking of multiple anterior branches of intercostal nerves (Th2 - 6) using a transversus thoracic muscle plane block. Reg Anesth Pain Med 2015;40(4):388.

[12] Buono RD, Costa F, Costa F, et al. Parasternal, pectointercostal, pecs and transverse thoracic muscle plane 
blocks: a rose by any other name would smell as sweet. Reg Anesth Pain Med 2016;41(6):791-2.

[13] Pawa A, Wight J, Onwochei DN, et al. Combined thoracic paravertebral and pectoral nerve blocks for breast surgery under sedation: a prospective observational case series. Anaesthesia 2018;73(4):438-43.
[14] Costa F, Strumia A, Remore LM, et al. Breast surgery analgesia: another perspective for PROSPECT guidelines. Anaesthesia 2020;75(10):1404-5.

[15] Versyck B, Groen G, van Geffen GJ, et al. The pecs anaesthetic blockade: a correlation between magnetic resonance imaging, ultrasound imaging, reconstructed cross - sectional anatomy and cross - sectional histology. Clin Anat 2019;32(3):421-9. 